\title{
About the best value of rake angle for cutting tools
}

\author{
Eugen Pămîntaş, ${ }^{1, *}$, and Felicia Veronica Banciu ${ }^{1}$ \\ ${ }^{1}$ Politehnica University Timişoara, Mechanical Faculty, Materials and Manufacturing Engineering \\ Department, 300222 Mihai Viteazu Av., Timişoara
}

\begin{abstract}
Regardless of whether the case of processing through methods of cutting metal, wood, plastics, stone, composite materials etc., the rake angle $(\gamma)$ is of major importance for energy efficiency and dynamic behaviour of cutting process, dimensional accuracy, work surface quality and pieces made cost. The paper examines the possibility of establishing the best value for the rake angle supposing two idealizations: one regarding the conditions in which cutting process takes place, and the second related to the simplifications aiming to facilitate a first stage of theoretical development of mathematical description for the chip forming process. Both idealizations are intended to individualize the influence that has the value of rake angle of the cutting tools on the process of chip forming in order to perceive the meaning of the link between the geometry of the cutting tool with other parameters of chips and by default with the work parameters set to machine-tool. While both validity and applicability of the mathematical relations obtained are negatively marked by the simplifying assumption which was appealed in achieving the approach, the highlighted findings may be good starting points for further research on the kinematics cutting depth and in the structure of the material being processed.
\end{abstract}

\section{Introduction}

When treating the problem of angle values for active part of cutting tools, the scientific literature abounds with recommendations, motivations and logical explanation of the variety of situations and practical working conditions.

All assertions summarized above represent in fact a very brief overview of these situations, to introduce an old question: it might determine the optimum value of rake angle at cutting from conditions which take into account the energy efficiency at metal cutting?

Attempts to answering this question were highly much in the last hundred years. The results are very good and briefly presented below: „At present, tool forces, tool temperatures, tool wear, component surface finish, and ease of chip disposal are all impossible to predict a priori with any certainty and/or without a large number of quasiempirically obtained constants. "Machining is an unconstrained metal working operation" [1]. Indeed, even more, because of the abundance of methods in an attempt to respond to the challenges caused by new materials for workpieces [2], by new materials [3] and new

${ }^{*}$ Corresponding author: eugen.pamintas@upt.ro 
types of tools [4], by the performance of new machine tools and more stringent requirements of customers in quality and cost, was said: ,...such an approach can hardly be called a science" [1].

The purpose of this paper is to examine the possibility of establishing the best value for rake angle $(\gamma)$.

\section{Problems of the main cutting angles}

In any chip removing process the sizes of main angles: clearance angle $(\alpha)$ and rake angle $(\gamma)$ are widely known to be crucial for the process [5-7].

The size of the clearance angle $(\alpha)$ must necessarily be positive for the cutting can be held and its maximum value is limited, particularly in terms of resistance of the active part of the tool and by the size of wear $\left(\mathrm{h}_{\alpha}\right)$ on the major flank $\left(\mathrm{A}_{\alpha}\right)$ of the tool (usually not exceeding $12^{\circ}$ and often coming within $5^{\circ} \div 10^{\circ}$ ).

The value of rake angle $(\gamma)$ is however of great importance to the mechanical work of plastic deformation and splitting chip, for:

- The temperature dissipated in tool.

- Chip and piece.

- The form of chip detached.

- Wear and tool life.

- The dynamic behaviour.

- The overall energy efficiency of the cutting process.

- The dimensional accuracy, surface quality, and for the final cost of the processed part.

If we were to limit ourselves only to the effects listed above, the best value for departure angle would be that which could provide:

- Minimum cutting efforts.

- The most powerful chip fragmented.

- The better surface smoothness of the processed part.

- The highest durability for the tool edge.

- The smallest amplitudes of vibration intensities of machine tools.

- The least harmful effects on others geometrical parameters of tool cutting as a whole.

- Lowest cost of operating the tool etc.

The rake angle being of such importance, it is not surprising that even industry standards normalized no less than three types ( 6 variants) of sharpening the rake face of cutting tool $\left(\mathrm{A}_{\gamma}\right)$, e.g. STAS350-82 and STAS R6781-83 [8], as opposed to one way of sharpening for clearing face of the cutting tool.

However, for choosing the value of the rake angle there are numerous recommendations in university courses, handbooks, design guides and professional literature, normative and standards of companies that manufacture cutting tools (e.g. Sandvik, Walter etc.).

Unlike the clearance angle, the rake angle can have values both negative and positive:

- Negative rake angle have the disadvantage of very big stresses on the part, high power consumption to the machine tool, poor quality of part surface manufactured and greater resistance of cutting tool peak and greater durability thereof;

All these reasons make that negative values for rake angle must only be used to roughing operations in the case of variant of sharpening with negative facet and their value does not exceed about $-8^{\circ}$.

- Positive rake angles are limited primarily by higher flexural strength of the cutting tool material and only subsequently by the coefficient of friction chip-tool.

For these reasons:

-it is usual recommended for rake angle values below $10^{\circ}$ (very rarely in steel finishing);

- and disc or prism shaped knives is reached and the value of $25^{\circ}$. 


\section{About Chip Formation}

\subsection{Work hypothesis}

The approach is based on two idealisation hypothesis:

- One concerning the conditions in which the cutting process takes place.

- The other, in connection with simplifications designed to ease, in the first stage development of theoretical mathematical description regarding the process of chips forming.

Both idealizations are intended to individualize the influence of rake angle cutting tools value has in the process of chip forming in order to perceive the meaning of the link between the geometry of the cutting tool with other chips parameters and default working parameters set to machine-tool.To facilitate understanding this paper's aim and the extent of the validity of its conclusions, it will bring some clarification on the meaning of the word "ideal" as used in paragraph beginning.

Ideal in the sense of this approach refers to conditions in which the cutting process, on the one hand:

- The contact between the workpiece and tool edge sector is made in a direction perpendicular to the main resultant cutting speed vector (Fig. 1).

- The length of the tool major cutting edge is at least equal to the length of depth of cut projection on that edge.

- The thickness (b) and the width (a) of the material layer to be removed from the workpiece (undetached chip) are constant throughout the machining phase;

- Undetached chip length is at least twice the depth of cut $\left(a_{p}\right)$,

- Kinematic parameters of the cutting process $\left(v, f, a_{p}\right)$ are constant during machining.

On the other hand, refers to introduce simplifications to ease - in this first phase of development theory- the mathematical description of the process of detachment of the chip:

- Cutting without using coolant.

- The tool major cutting edge is perfectly sharpened.

- The workpiece material is homogenous and isotropic.

- There is no friction between the tool-piece-chip and does not form build-up edge and other similar phenomena.

In these circumstances, the ideal longitudinal turning will be characterized by parameters defined in the tool-in-hand system, as presented, with the notation according to ISO 3002 / I-1977 [8] in Figure 1.
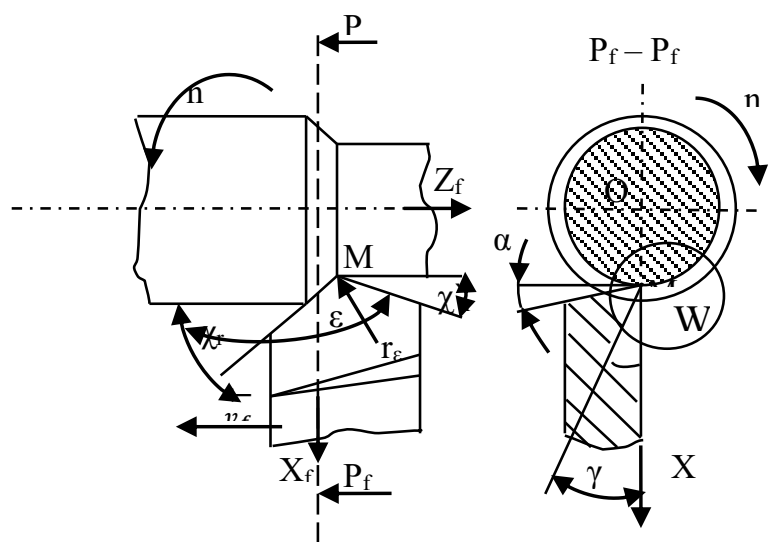

Fig. 1. The ideal longitudinal turning scheme. 
For example and support of theoretical future development in Figure 1 is shown schematically the case of longitudinal turning, that captured a $\Delta$ t time in a turning phase of a cylindrical steel workpiecewith mechanical and structurally homogeneous and isotropic known, using constant cutting conditions.

\subsection{Ideal chip model}

As result of cutting movements, the tool tensions a small material volume placed ahead it (Fig.2). Packages of plastic and elastic deformed crystals begin to slide against each other, orienting after sliding plane B-B (Fig.2) inclined with $\Phi_{2}$ angle upon the cutting direction. When the value of strengths exceeds the tensile strength limit of the workpiece material, chip detaching occurs after shearing plane A-A, inclined with angle $\Phi_{1}$ to cutting direction.

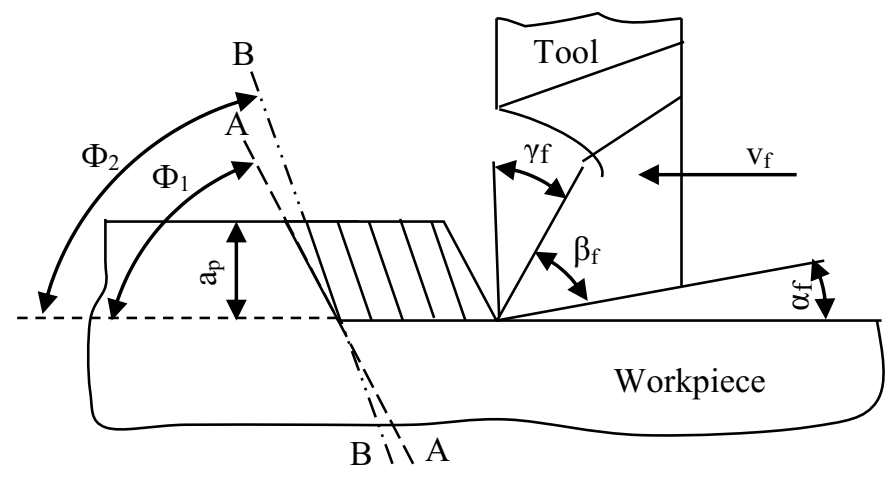

Fig. 2. Chip detaching mechanism.

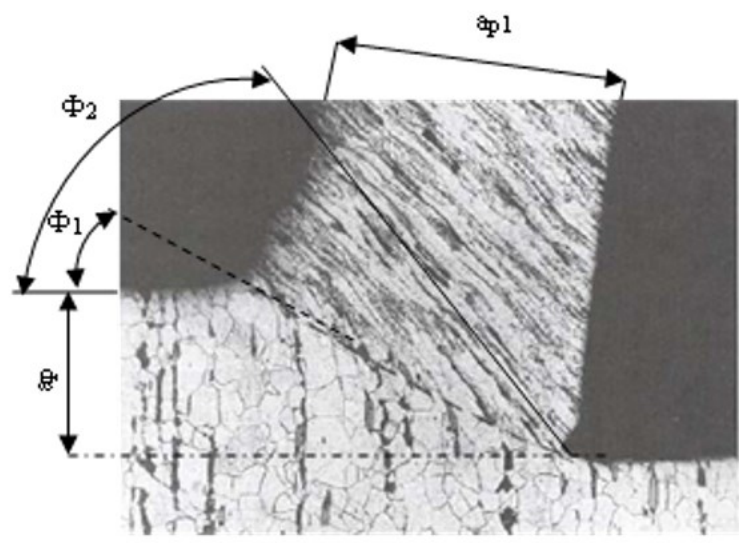

Fig. 3. Practical example of undetached chip material [9].

This theoretical mechanism of chip formation has often been highlighted by numerous experiments and metallographic analyses ofundetached chip material [9, 1], as shown in Figure 3.

From the same experiments among conclusions was find that angle values $\Phi_{1}$ and $\Phi_{2}$ depend mainly on chip elements (a- thickness, b-width), on frictional forces between the chip and tool rake face $\left(\mathrm{A}_{\gamma}\right)$, rake angle $\gamma$ etc. and that the difference between their sizes is about: $\Phi_{2}-\Phi_{1}=20^{\circ}$ to $30^{\circ}[10]$.

Also, detached chip shape is severely affected by: the physical properties of the material to be cut, the chip area, the angle $\gamma$, and the cutting speed $\left(\mathrm{v}_{\mathrm{c}}\right)$. 
Because the friction phenomena, the mechanical and thermal stresses, detached chip suffer deformation thus occurring chip shortening and thickening: $K_{m}=a_{p l} / a_{p}\left(a_{p l}\right.$ detached chip thickness $a_{p}$ - unbroken chip thickness; experimental observation of the compression ratio of the thickness of the chip Km values in the range $1.5 \div 4$ ) [11].

In the ideal case of an isotropic and homogeneous workpiece material, in the absence of friction between tool-chip-workpiece, for orthogonal turning with constant working parameters, it can be assumed that the twinning angle and the shear have the same value and more this value is one of the characteristic peculiar to type of material.

The chip resulting in these assumptions would be one idealized, undeformed and cold for which the angles $\Phi_{2}=\Phi_{1}=\Phi$, undetached chip has the same dimensions with the detached one (see Fig. 4) and so would have $K_{m}=1\left(a=a_{p l}=a_{p}\right), b=b_{1}$ width, length $1=1_{0}$ etc.

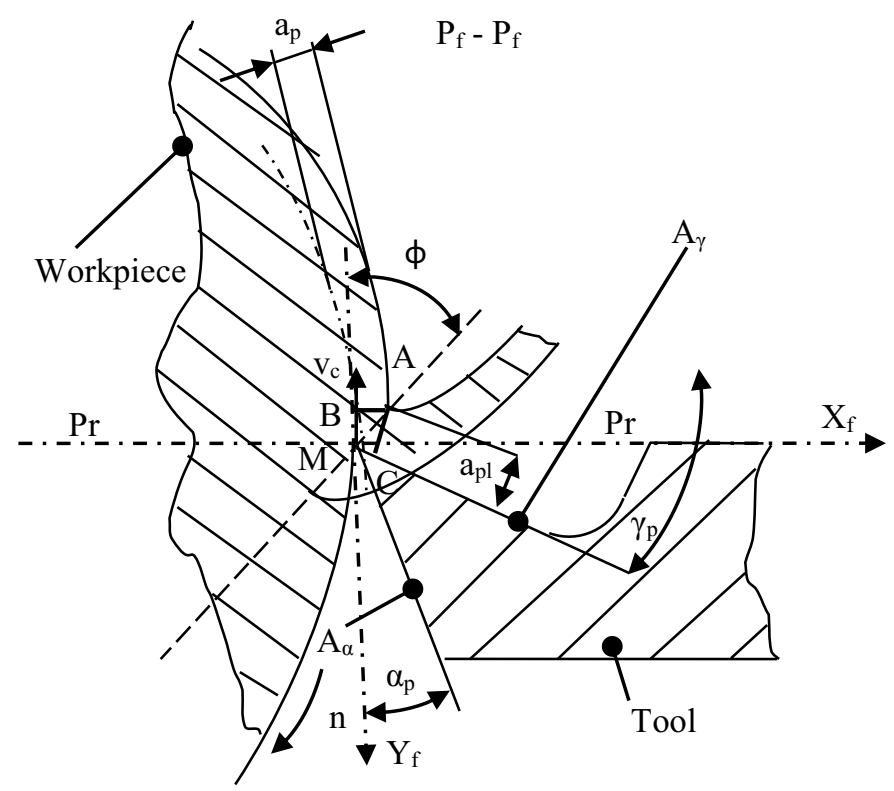

Fig. 4. Chip formation mechanism scheme for calculus.

\section{Ideal rake angle}

\subsection{Establishing of calculus relation}

In the above mentioned assumptions are searched in the following an expression of a relationship of dependency between the cutting tool rake angle $\gamma$ and the workpiece material natural shear angle $\Phi$. Thus, from MAB and MAC triangles in Figure 4, $\overline{\mathrm{MA}}$ segment is developed:

$$
\overline{\mathrm{MA}}=\frac{\mathrm{a}_{\mathrm{p}}}{\sin \Phi}=\frac{\mathrm{a}_{\mathrm{pl}}}{\cos \left(\gamma_{\mathrm{p}}-\Phi\right)}
$$

Using the notation $\mathrm{K}_{\mathrm{m}}=\mathrm{a}_{\mathrm{p}} / \mathrm{a}_{\mathrm{p}}$ from equation (1) results:

$$
K_{m}=\cot \Phi \cos \gamma_{p}-\sin \gamma_{p}
$$

In equation (2) $\sin \gamma_{p}$ and $\cos \gamma_{p}$ will be expressed using $\tan \gamma_{p} / 2$, designating $\tan \gamma_{p} / 2=$ $t$. Next, developing the equation 2 will be obtained a quadric with $t$ variable. 
Solving this eq. it is obtained for $\gamma_{p}$ the dependency relation in form of equation (3).

$$
\gamma_{p 1,2}=2 \tan ^{-1} \frac{\tan \Phi \pm \sqrt{\left(1-K_{m}^{2}\right) \operatorname{tg}^{2} \Phi+1}}{K_{m} \tan \Phi+1}
$$

\subsection{Testing the calculus relation}

In the specialized literature are presented ranges of values among which - depending on working conditions - are usually coefficients, reports, cutting angles, etc., among which are found also those of interest in this case: $\mathrm{Km}, \Phi$ and $\gamma$.

Table 1. Some solutions of equation (3) solving.

\begin{tabular}{|c|c|c|c|c|c|c|c|c|}
\hline \multirow{2}{*}{$\Phi$} & \multicolumn{2}{|c|}{$\mathbf{5 0}^{\circ}$} & \multicolumn{2}{c|}{$\mathbf{6 0}^{\circ}$} & \multicolumn{2}{c|}{$\mathbf{7 0}^{\circ}$} & \multicolumn{2}{c|}{$\mathbf{8 0}^{\circ}$} \\
\cline { 2 - 9 } $\mathbf{K}_{\mathbf{m}}$ & \multicolumn{2}{|c|}{$\gamma_{\mathbf{p}}$} & \multicolumn{2}{c|}{$\gamma_{\mathbf{p}}$} & \multicolumn{2}{c|}{$\gamma_{\mathbf{p}}$} & \multicolumn{2}{c|}{$\gamma_{\mathbf{p}}$} \\
\hline & 1 & 2 & 1 & 2 & 1 & 2 & 1 & 2 \\
\hline 1 & $90^{\circ}$ & $10^{\circ}$ & $90^{\circ}$ & $30^{\circ}$ & $90^{\circ}$ & $50^{\circ}$ & $90^{\circ}$ & $70^{\circ}$ \\
\hline 0.67 & $109^{\circ} 07^{\prime}$ & $-09^{\circ} 7^{\prime}$ & $114^{\circ} 33^{\prime}$ & $05^{\circ} 28^{\prime}$ & $120^{\circ} 59^{\prime}$ & $19^{\circ} 1^{\prime}$ & $128^{\circ} 38^{\prime}$ & $31^{\circ} 14^{\prime}$ \\
\hline 0.50 & $117^{\circ} 30^{\prime}$ & $-17^{\circ} 29^{\prime}$ & $124^{\circ} 21^{\prime}$ & $-04^{\circ} 21^{\prime}$ & $131^{\circ} 57^{\prime}$ & $08^{\circ} 1^{\prime}$ & $140^{\circ} 32^{\prime}$ & $19^{\circ} 31^{\prime}$ \\
\hline 0.4 & $122^{\circ} 08^{\prime}$ & $-22^{\circ} 09^{\prime}$ & $129^{\circ} 45^{\prime}$ & $-09^{\circ} 44^{\prime}$ & $137^{\circ} 53^{\prime}$ & $02^{\circ} 6^{\prime}$ & $146^{\circ} 48^{\prime}$ & $13^{\circ} 12^{\prime}$ \\
\hline 0.33 & $125^{\circ} 22^{\prime}$ & $-25^{\circ} 22^{\prime}$ & $133^{\circ} 23^{\prime}$ & $-13^{\circ} 23^{\prime}$ & $159^{\circ} 29^{\prime}$ & $-01^{\circ} 56^{\prime}$ & $151^{\circ}$ & $08^{\circ} 58^{\prime}$ \\
\hline 0.29 & $127^{\circ} 09^{\prime}$ & $-27^{\circ} 9^{\prime}$ & $135^{\circ} 29^{\prime}$ & $-15^{\circ} 28^{\prime}$ & $144^{\circ} 13^{\prime}$ & $-04^{\circ} 11^{\prime}$ & $153^{\circ} 24^{\prime}$ & $06^{\circ} 36^{\prime}$ \\
\hline 0.25 & $128^{\circ} 56^{\prime}$ & $-28^{\circ} 57^{\prime}$ & $137^{\circ} 31^{\prime}$ & $-17^{\circ} 30^{\prime}$ & $146^{\circ} 25^{\prime}$ & $-06^{\circ} 25^{\prime}$ & $155^{\circ} 46^{\prime}$ & $04^{\circ} 15^{\prime}$ \\
\hline 0.22 & $130^{\circ} 16^{\prime}$ & $-30^{\circ} 17^{\prime}$ & $139^{\circ}$ & $-18^{\circ} 59^{\prime}$ & $148^{\circ} 03^{\prime}$ & $-08^{\circ} 4^{\prime}$ & $157^{\circ} 30^{\prime}$ & $02^{\circ} 39^{\prime}$ \\
\hline
\end{tabular}

By most times the extent of the ranges where can take values the cutting sizes covers all the working conditions and cases. However, most often, the practice has demonstrated that measurements that are at limits of ranges, and those near the middle thereof, are rarely attained. For this reason, in Table 1 was tested relationship (3) using the recommended values for $\mathrm{K}_{\mathrm{m}}(0.22 \div 0.67)$ and $\Phi\left(45^{\circ}\right.$ to $\left.80^{\circ}\right)$ and the obtained results for rake angle were compared with those recommended by theorists and researchers in the cutting field and with those used by manufacturers and industrial users of turning tools [12-14].

Table 1 presents the full results of calculations (including ideally $\mathrm{K}_{\mathrm{m}}=1$, regarded as the simplifying assumptions used in reference to the relationship deduction for calculating the angle $\gamma$ ) for some random values of the parameters $\mathrm{K}_{\mathrm{m}}$ and $\Phi$. Both solutions are obtained from equation (3) for $\gamma_{\mathrm{p} 1}$ and $\gamma_{\mathrm{p} 2}$ were tabulated in order to observe both values and as such the tendency of their variation.

Analysing the results in Table 1 it can be retained as relevant for the purposes of this paper the following basis:

- $\gamma_{\mathrm{p} 1}$ is a solution without practical correspondent and should not be considered only as a marker for checking the keeping of upward trend with increasing the value of shear angle $\Phi$ and increasing the chip deformation (decrease of $\mathrm{K}_{\mathrm{m}}$ );

- $\gamma_{\mathrm{p} 2}$ solution is credible but other factors involved in cutting (failure conditions for chip detachment, friction angle between the material and tool, the prohibitive cutting forces, tool cutting edge strength, machined surface quality, etc.) make that only the values marked in grey in table 1 to be relevant for practice;

- Cutting conditions considered in case of ideal assumptions are obtained for $\gamma_{\mathrm{p}}$ angle values in range: $\gamma_{\mathrm{p}} \in\left(-8^{\circ} \div 13^{\circ}\right)$, when the chip contraction coefficient $\mathrm{K}_{\mathrm{m}} \in(0.22 \div 0.5)$ and shear angle of workpiece material is in the range of $\Phi \in\left(70^{\circ} \div 85^{\circ}\right)$. 


\section{Conclusions}

Although both the validity and applicability of mathematical relations obtained are marked negative by simplifying assumptions (which was called in realizing the presented approach), highlighted findings may be good starting points for further research into the kinematics of cutting and structure of the material being processed thoroughgoing study:

- Experimental testing meaning to evaluate the validity of these theoretically findings will be restricted to areas $\mathrm{K}_{\mathrm{m}} \in(0.25 \div 0.4)$ (low degree of chip shrinkage is very rare in practice and high degrees of shrinkage are prohibitive from an energetic point of view) and $\Phi \in$ $\left(75^{\circ}\right.$ to $\left.80^{\circ}\right)$.

- $\gamma_{\mathrm{p} 2}$ solutions will be considered only in relation (3) - with the "minus" between factors from fraction denominators.

Who would not like that knowing the shear angle of workpiece material $\Phi$ - provided by the manufacturer of raw materials - and requiring a certain value for the desired degree of chip contraction - for reasons of energy, dynamic machine-tool behaviour, chip removing process etc. - choosing the tool rake angle $\gamma$, the most favourable or optimal?

The idea of looking for a link between the shear angle $\Phi$ of each type of material and the rake angle $\gamma$ that would provide the smallest chip breaking effort to the cutting operations, more than the validity of the deduced relationship, should be considered - more chosen due to the many simplifications in the hypothesis - as just a "scaffold", necessarily to lift any subsequent "construction". It is known that operating parameters, cutting conditions, material properties and cutting tool etc. influences the values of the cutting angles optimal to the intended purpose. However, the authors believe it would be desirable to know the value of the rake angle that would provide the lowest energy consumption. This is the point around which they revolve choice of values to optimize the criteria chosen by the client for each case. It would therefore be desirable to develop future research, not wasting precious time mastering scaffolding, confusing "platform" with "construction".

It should be established multidisciplinary research teams with specialists in cutting, materials physics, metallographic analyse that would work after such an experimental program that tries to solve the question of naturally shear angle of the material to be cut.

It could be another step in the sum of which would provide one of the most desired technical problems: full control of the cutting process

This research acknowledges to Walter Tools SRL, Timişoara Romania and Universitary Association of Manufacturing Engineering in providing information on the practice of metal cutting and support financial funding for this paper. The valuable comments from anonymous reviewers are greatly acknowledged to help improve the paper's quality.

\section{References}

1. P.K. Wright, D.A. Bourne, Manufacturing Intelligence (Addison-Wesley Publishing Company, USA, 1988)

2. M.P .Groover, Fundamentals of Modern Manufacturing Materials, (Processes and Systems, $4^{\text {th }}$ ed., John Wiley \& Sons Inc., New York, 2010)

3. S.R. Maity, P. Chatterjee, S. Chakraborty, Materials \& Design, 36, 372 (2012)

4. $* * *$ http://www.ttonline.ro/tag/walter-tools, accessed on 13.03.2017

5. Y. Altintas, Manufacturing automation: metal cutting mechanics, machine tool vibrations, and CNC design (Cambridge University Press, 2012)

6. L. Juneja, G.S. Sekhon Nitin Seth, Fundamentals of metal cutting and machine tools (New Age International Publishers, New Delhi, 2005)

7. M.E. Trent, K. Paul, K.P. Wright, Metal Cutting (Elsevier Inc., 2000) 
8. *** Cutting tools for metal manufacturing. Romanian standard, II, (Technical Ed., Romania, 1987)

9. J.S. Colton, Manufacturing processes and Systems. Machining overview \& basics of chip formation mechanics, (Georgia Institute of Technology, GIT, 2009)

10. I. Pop, Cutting tools design (Politehnica Publishing House, Timişoara, Roamania, 1992)

11. I. Dumitrescu, Cutting tools design. Lab. Guide (UniversitasPublisching House, Petroşani, Romania, 2016)

12. $* * *$ http://engineeringhut.blogspot.ro/2010/11/types-of-chips.html, accessed: 13.03.2017

13. ${ }^{* * *}$ https://www.slideshare.net/ilieureche/bazele-aschieriiaranjata, accessed: 26.02 .2017

14. R. Krehel', D. Krchova, M. Kočiško, Key Engineering Materials, 669, 382 (2016) 